\title{
Mapping access to food in a deprived area: the development of price and availability indices
}

\author{
Angela JM Donkin ${ }^{1, *}$, Elizabeth A Dowler ${ }^{1}$, Simon J Stevenson ${ }^{2}$ and Sheila A Turner ${ }^{3}$ \\ 'Public Health Nutrition Unit, London School of Hygiene and Tropical Medicine, Keppel Street, \\ London WCIE 7HT, UK: ${ }^{2}$ Environmental Epidemiology Unit, London School of Hygiene and Tropical Medicine, \\ Keppel Street, London WC1E 7HT, UK: ${ }^{3}$ Institute of Education, 20 Bedford Way, London WC1H OAL, UK
}

Submitted 4 January 1999: Accepted 13 July 1999

\begin{abstract}
Objective: To develop and map indices to illustrate variation in the cost and availability of healthy food.

Design: Two contiguous wards in London were selected by virtue of their high Carstairs deprivation scores. A $2-\mathrm{km}$ area was defined around a randomly chosen central point. All retail outlets selling food within the area were visited and their location recorded. A list of foods, acceptable to the local ethnically diverse population, which met current dietary guidelines, was devised. Data on the availability and price of 71 food items were collected. Indices were developed using SPSS and mapped using Geographic Information System (GIS) software.

Results: Information on availability and prices were collected from 199 outlets. The mean price index shows how expensive a shop is relative to other shops in the area. The least cost index shows the relative expense of a shop using the cheapest ways of buying their range of foods. Shorthand indices were tested, using data on 19 of the 71 prices. Availability indices are also discussed, including a green availability index and a fresh green availability index. Illustrative maps of the shop locations and the mean price index and fresh green availability index are shown.

Conclusions: Data can be collected and indices developed which indicate geographic variation in shop 'expensiveness', and in the price and availability of healthy food. GIS software can be used to map these indices, to identify areas with high food prices or low availability.
\end{abstract}

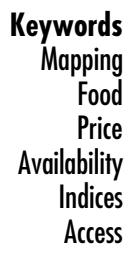

'We recommend policies which will increase the availability and accessibility of foodstuffs to supply an adequate and affordable diet ... We recommend the further development of policies which will ensure adequate retail provision of food to those who are disadvantaged, ${ }^{\text {. }}$

One in four of the British population, 13.8 million people, live in households with incomes below the European poverty line of half the average incomes; 9.6 million are in households receiving income support (means tested social provision) and the rest live on low or insecure wages ${ }^{2}$.

The National (Household) Food Survey published annually by the government ${ }^{3}$ consistently shows that nutrient intakes are less likely to be adequate in the lowest income groups compared to the highest. In addition the survey of nutritional status in British adults ${ }^{4}$ found that men and women who were unemployed, or in households claiming benefit or in social classes IV and V, had significantly lower intakes of many vitamins (especially vitamin C, carotene and vitamin E) and minerals (especially iron) than people not in these categories. Other studies show similar results ${ }^{5-7}$.
Many foods which are integral to a healthy diet are perceived as a luxury by those with low incomes ${ }^{8}$ and are an expensive form of calories ${ }^{9}$; such foods include fruits, vegetables and fish. In addition many healthier alternatives carry a price premium, for instance wholemeal bread, monounsaturated oils and lean meat ${ }^{10-12}$. The relative expense of healthy foods is just one of the food price issues currently on research agendas; another is the issue of price variability between shops. Food is generally more expensive in corner shops, convenience stores and independent small supermarkets than in large supermarkets or discounters - for basic groceries and for those food items recommended for a healthy diet ${ }^{13,14}$. Piachaud and Webb found that, on average, basic foodstuffs cost $24 \%$ more in small stores than in supermarkets; taking supermarket own brands into account, the differences in costs were $60 \%$. They calculated that a household on benefits would have to spend $25 \%$ more of their income on food if they could not get to a large supermarket or street market ${ }^{13}$.

The price of healthy food and the variation between prices is, therefore, of major concern for those living on 
low incomes. Many of the poorest in Britain are concentrated in local authority housing in inner cities and there is evidence to suggest a continuing geographical polarization of income inequalities ${ }^{15}$. In many of these areas, shops and banks have withdrawn, partly because the inhabitants spend little and partly because of the retail concentration in superstores (defined as having a total floor surface area of $>7620 \mathrm{~m}^{2}$ ) designed primarily for car $\operatorname{access}^{16,17}$.

This situation poses questions about physical and economic access to reasonable food for those on low incomes: (i) how do we define access?, (ii) how do we measure access? and (iii) how do we improve access? The need for a systematic method to measure access to food in the United Kingdom was highlighted by the Low Income Project Team of the Nutrition Task Force in 1996, with recommendations for the development of indices of price and availability ${ }^{16}$. The problem of access to healthy food at a reasonable price has also been acknowledged in recent government policy documents ${ }^{1,14}$.

This paper reports ongoing research into defining and mapping access to healthy food, addressing those questions above. It describes the development of indices to show variation in the price and availability of healthy food at a local level. These indices can then be mapped, using GIS software, with local geographical and socioeconomic information, to define and describe areas with varying levels of provision. It is not assumed that because there is provision there is sufficient access but rather that provision is one of the key factors which needs to be systematically defined and examined before access, be it economic or physical, can be measured. We suggest that the indices described could be mapped with local information on road networks, public transport routes, population figures and deprivation indices, to enable local health authorities, councils or retailers to identify and target areas where it appears that there may be less physical and/ or economic access to shops that provide a range of healthy food at a reasonable price.

The research is based in a deprived area in London. A geographical perspective relating to physical access to food in a defined area is pertinent to the measurement of economic access, given the geographical concentration of people living on low incomes.

Further work, out of the scope of this paper, has used the indices described here to target places which appear to have poorer food access, and, using participatory appraisal techniques, has engaged the communities in these areas in further exploration of their local and personal food access.

\section{Methods}

Two contiguous wards in London were selected by virtue of their high positive Carstairs deprivation scores ${ }^{18}$ and in consultation with the local health authority and local authority. A 2-km area was defined around a central point located between two housing estates in these wards. A full census of all retail outlets selling food (including newsagents, garage forecourts, etc.) within the area was conducted. The $2-\mathrm{km}$ radius was selected on the basis that it included a wide range of outlets including a choice of superstores and an area with shops specializing in the sale of Asian foods. Subsequent participatory appraisal work confirmed the choice of area as reasonable.

Eighty-six per cent of the local population was made up of four ethnic groups ${ }^{19}$. At the 1991 census, $44 \%$ of the population could be classified as white UK/Irish, 25\% black Caribbean, 9\% African and 8\% Indian. A datasheet for collecting information about food prices and availability was constructed so that foods acceptable to the four ethnic groups were included, with enough flexibility built in to price standard packet sizes and loose goods, in addition to the largest and smallest sizes available. The range of foods and quantities were chosen such that they would:

1. Contribute to a 'healthy diet'.

2. Reflect the preferences of the ethnic mix within the area.

3. Take into account different household sizes.

4. Take into account ethnic variations in shopping practices (e.g. in terms of the quantity of an item bought at any one time).

5. Be acceptable to the local population (i.e in terms of taste preferences and normal eating patterns).

6. Reflect the fact that many people within the area are living on low incomes.

In constructing the list of foods to be included on the datasheet, we drew on previous research with regards to typical food patterns ${ }^{3,20-23}$. This was supplemented by information collected in the local area on what local people from different ethnic groups typically bought. This research was relatively informal, conducted through discussions with local community groups (namely two tenant association groups who met to discuss issues relating to their 'block', the Asian Women's Group, two nurseries where mothers also attended, and a kindergarten) and through meetings with the local health worker and community dietician who had extensive local knowledge of the eating habits of the local residents. The groups were selected on the basis that they represented a range of different types of people living in the area. In addition opportunistic interviewing took place outside a small supermarket, and receipts were collected outside one of the main local superstores. Shoppers' self-defined ethnicity, current postcode, duration of residence in the country and family size were noted. From this published and local information four 'healthy' lists were derived which represented foods which would be seen as acceptable, given current eating and shopping habits, by the four local ethnic groups. The foods in the lists are not 
all mutually exclusive and indeed some foods, not instantly recognizable as being from any of these cultures, were common to all (for instance canned plum tomatoes and pasta). Table 1 shows the foods which were chosen to represent a typical, though not prescriptive, range of foods which would be bought by the majority of a given ethnic group.

By default, collecting information on the prices of these foods provides information as to their physical availability within a shop; availability in this sense represents presence and not the ability of someone to afford the item. However, to put information on the availability of these items into context, the availability of a wider range of food items was also collected, to build up a fuller picture of (healthy) food availability. For instance, for each shop, information was collected on the extent of the range available in key products: fresh, tinned, frozen fruits and vegetables; fresh and frozen fish and meat; breakfast cereals; and the availability of alternatives and 'nonhealthy' products (e.g. full fat milk, sweets and chocolates, carbonated drinks).

For each shop the datasheet was used to collect information on: availability; the prices of a subset of healthy foods; address and postal code; subjective measures of the quality of fruits and vegetables and cleanliness of the shop; nearby bus stops; nearby shops; and opening hours.

The datasheet was piloted for 1 week in December 1997 in order to refine the quantities and descriptions of products. Actual data collection took place between late

Table 1 Foods included in the price survey

\begin{tabular}{|c|c|c|c|}
\hline White UK/Irish & Caribbean & African & Gujarati Hindu \\
\hline Wholemeal bread & Wholemeal bread & Wholemeal bread & Wholemeal bread \\
\hline White bread & White bread & White bread & White bread \\
\hline White pasta & White pasta & White pasta & White pasta \\
\hline Potatoes (old) & Potatoes (old) & Potatoes (old) & Potatoes (old) \\
\hline Potatoes (new) & Potatoes (new) & Potatoes (new) & Potatoes (new) \\
\hline Cornflakes & Cornflakes & Cornflakes & Cornflakes \\
\hline Weetabix & Weetabix & Weetabix & Weetabix \\
\hline Long grain rice & Yam & Yam & Basmati rice \\
\hline \multirow[t]{3}{*}{ Frozen chips } & Ripe plantain & Ripe plantain & \multirow[t]{3}{*}{ Mid brown chapatti flour } \\
\hline & Green plantain & Green plantain & \\
\hline & Long grain rice & Long grain rice & \\
\hline Semiskimmed milk & Semiskimmed milk & Semiskimmed milk & Semiskimmed milk \\
\hline Cheddar & Cheddar & Cheddar & Cheddar \\
\hline Low-fat fruit yoghurt & Low-fat fruit yoghurt & Low-fat fruit yoghurt & Low-fat fruit yoghurt \\
\hline Polyunsaturated spread & Polyunsaturated spread & Polyunsaturated spread & Polyunsaturated spread \\
\hline Olive oil & Olive oil & Olive oil & Olive oil \\
\hline Sunflower oil & Sunflower oil & Sunflower oil & Sunflower oil \\
\hline Eggs & Eggs & Eggs & Eggs \\
\hline Apples & Apples & Apples & Apples \\
\hline Bananas & Bananas & Bananas & Bananas \\
\hline Oranges & Oranges & Oranges & Oranges \\
\hline Satsumas or similar & Satsumas or similar & Satsumas or similar & Satsumas or similar \\
\hline Pears & Pears & Pears & Pears \\
\hline Grapes & Mango & Mango & Coconut \\
\hline Strawberries & Grapes & Pineapple & \\
\hline Tinned tomatoes & Tinned tomatoes & Tinned tomatoes & Tinned tomatoes \\
\hline Onions & Onions & Onions & Onions \\
\hline Fresh tomatoes & Fresh tomatoes & Fresh tomatoes & Fresh tomatoes \\
\hline Carrots & Carrots & Carrots & Carrots \\
\hline Cabbage & Cabbage & Cabbage & Cabbage \\
\hline Frozen peas & Frozen peas & Pepper & Frozen peas \\
\hline Lettuce & Ackee & Lettuce & Karella \\
\hline Cucumber & Okra & Okra & Okra \\
\hline Pepper & Pepper & Cucumber & Lettuce \\
\hline Broccoli & Chowchow & Chowchow & Cucumber \\
\hline \multirow[t]{2}{*}{ Mushroom } & Aubergine & Mushroom & Aubergine \\
\hline & Spinach & & Spinach \\
\hline Baked beans & Baked beans & Baked beans & Baked beans \\
\hline Kidney beans (canned) & Kidney beans (dried) & Lentils & Lentils (masoor dhal) \\
\hline Lean beef mince & Goat & Black eye beans & Lentils (moong dhal) \\
\hline Pork fillet/escalope & Pork fillet/escalope & Pork fillet/escalope & Lentils (toor dhal) \\
\hline Whole frozen chicken & Whole frozen chicken & Whole frozen chicken & Kidney beans (dried) \\
\hline Frozen chicken portions & Frozen chicken portions & Frozen chicken portions & Chick peas \\
\hline Fresh chicken portions & Fresh chicken portions & Fresh chicken portions & Black eye beans \\
\hline Fish fingers & Fish fingers & Fish fingers & Almonds \\
\hline Fresh/frozen cod/haddock fillets & Fresh/frozen snapper/malabar & Fresh/frozen cod/haddock fillets & \\
\hline Fresh mackerel/herring & Salted fish & Fresh mackerel/herring & \\
\hline Tinned sardines & Tinned sardines & Tinned sardines & \\
\hline
\end{tabular}


December 1997 and April 1998. Price variation over that period and the reliability of the data collection was checked on a subset of shops. While slight price variation did exist within the shops there was no consistent seasonal pattern.

\section{Indices}

In order to begin to measure economic access it is necessary to create indices of food prices for an outlet, given the food that is stocked. Constructing price indices for shops is relatively complex, firstly because not all shops will stock all items, and secondly, because not all items will be sold in the same quantities. Indeed foods may be available in multiple quantities. Price indices for each shop were constructed in steps, as follows.

1. For each individual weight/size of food the cost per kilogram was calculated; for example the cost per kilogram of baked beans if bought in a $205 \mathrm{~g}$ tin, and the cost per kilogram of baked beans if bought in a $410 \mathrm{~g}$ tin. The mean cost of buying each item in a particular quantity within the area was then calculated. For items with no weight (for instance iceberg lettuce or cucumber) the mean cost was calculated without conversion into kilograms.

2. The price for each weight/size of food in a particular shop was then expressed in relation to the mean price of that weight/size in all shops. This was achieved using Z-scores - the number of standard deviations a product price is from the mean product price. This generates an index for the relative expense of a shop for one product in one size.

3. The cost of the food item, given all the quantities stocked in the shop can then be summarized. For instance it is possible to calculate the mean price of buying food item $x$ in the shop given all the quantities available, and then to relate that mean price, in z-scores, to the mean cost of buying food item $x$ in all shops, hence producing a mean price index for food $x$. Similarly, given all quantities, we can take the minimum cost per kilogram of buying food item $x$ in the shop, and relate that, using $z$-scores, to the mean minimum cost of buying food item $x$ in all shops, giving a least cost index for food $x$.

4. To calculate an index for a shop for a range of products, the mean of all z-scores for each shop was used. This enables us to say that, of all the shops, for what they stock, shop b is expensive for the area and shop c is cheap. Thus we can calculate the mean price index for all products, or the least cost index for all products.

We were particularly interested in access to fruits and vegetables because much research has linked adequate fruit and vegetable consumption with the prevention of chronic diseases, many of which have a higher incidence within poorer communities. Hence we developed a green availability index and a fresh green availability index. The green availability index is based upon the number of different types of fruits and vegetables in each of the fresh, frozen, canned and juice categories recorded by the collector. If there were more than 10 varieties in any one category then ' $>10$ ' was recorded by the data collector.

\section{Sample}

Using the datasheet, data on the availability of 123 food items and the price of 71 food items (the total number of foods that made up the four healthy lists for different ethnic groups), in different quantities, were collected from 199 outlets selling food. As previously mentioned availability information was collected on a wider range of foods in order to be able to place the availability of the foods representing the healthy lists into context.

Two hundred and ten outlets were approached but for 11 we only have information on the nature of the shop and its location, due to difficulties in data collection. Of these 199 outlets, only 166 of the remaining outlets actually stocked some of the 71 'healthy foods' costed.

\section{Results}

Figure 1 shows the geographic distribution of the mean price index for all products on the healthy food list; i.e. the relative expense of a shop, given what is stocked, if the mean price of buying a food item in a shop is chosen. Each circle represents the cost of buying food at a particular postcode (the mean price index of all the food shops in that postcode) in relation to the mean cost of buying food in the whole area. The circles represent quintiles of the z-score distribution. The white circles represent postcodes where the food $\operatorname{shop}(s)$ are relatively inexpensive and the black circles postcodes where the shops are relatively expensive. The data shown on the map suggest there are fewer postcodes where food shops are relatively expensive. Further analysis has shown that postcodes which contain relatively expensive food shops characteristically have only one food outlet, which tends to be a petrol station, newsagent or off-licence, particularly the former. Indeed one petrol station charged $£ 1.89$ for Weetabix, 69p for white bread, £1.09 for $500 \mathrm{~g}$ of pasta, $42 \mathrm{p}$ for milk and $49 \mathrm{p}$ for a $410 \mathrm{~g}$ tin of baked beans. If one was to buy these five items from that petrol station it would cost $£ 1.77$ more than the mean price for the area, and $\$ 3.21$ more than the cheapest way of buying them in the area.

The range of actual prices for a subset of products with standard weights is shown in Table 2, for shops not including petrol stations, newsagents and off-licences and for just petrol stations, newsagents and off-licences. As the figures show, food prices vary tremendously. Taking the six products (Weetabix, semiskimmed milk, pasta, white bread, wholemeal bread and baked beans) it is possible to 


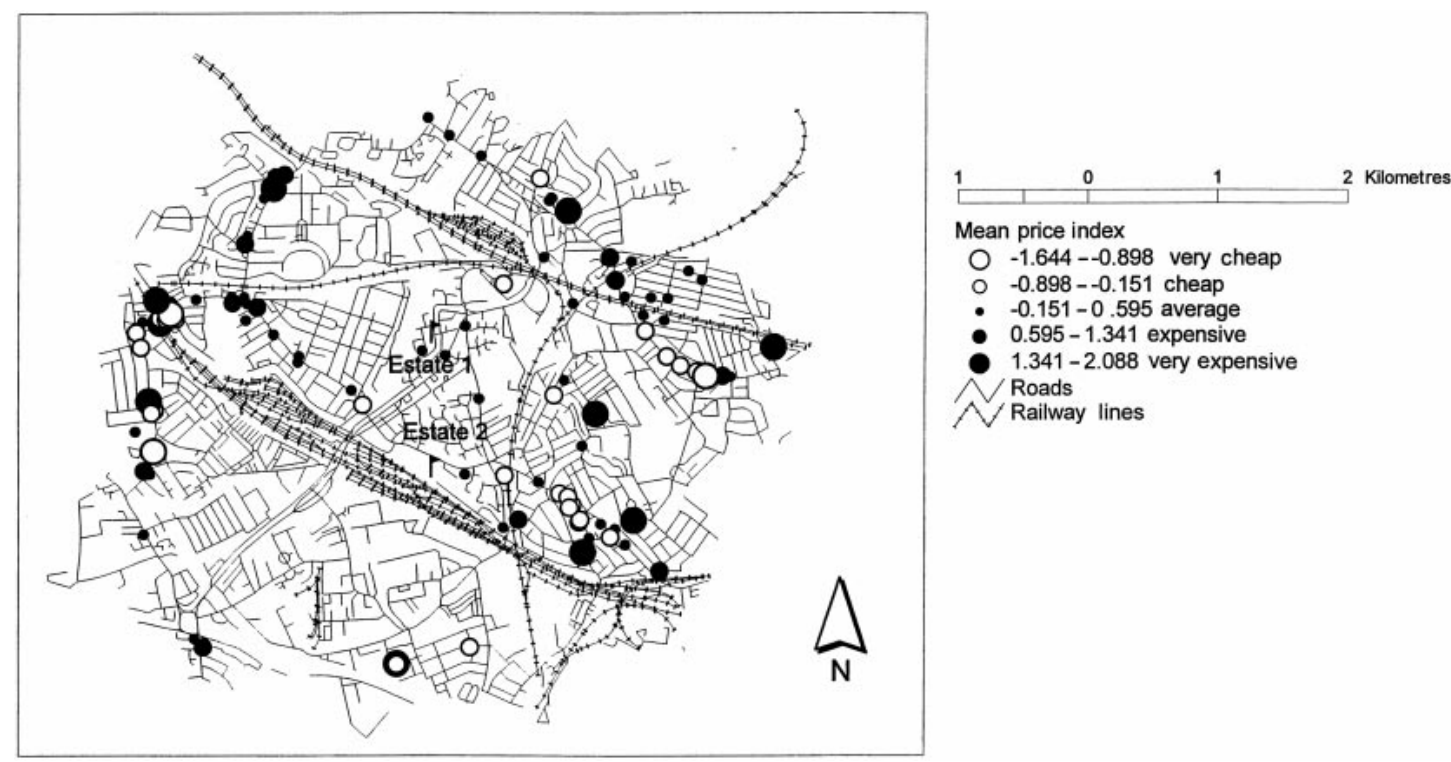

Fig. 1 Relative expense of food in postcodes in a deprived urban area given the mean cost of buying food items from shops. (Data for map: (c) Automobile Association, for railways, and (c) Bartholomew, for roads)

spend four and a half times as much on them than the cheapest price. These products were not selected because price variation was suspected but because they were of standardized weight and would be salient to the reader. Of these six, all were more expensive in petrol stations, newsagents and off-licences, and three items were significantly more expensive. If the researcher wished to present a picture of the price distribution of shops which are likely to be used more frequently then it would be feasible to exclude very expensive shops from the analysis.

\section{Condensed price index}

One of the aims of this project is to enable local authorities or health authorities to complete a quick surveillance of the physical and economic access problems in their area. Therefore the possibility of creating indices based on a subset of the above data was explored. The majority of the variability in the indices derived from all the 71 food items priced could be explained by indices derived for the 'common' group of products which were included in the shopping list for all the ethnic groups. These are shown in the first 17 rows of Table 3. (Although strict Hindus would not eat eggs, it was clear from the previous qualitative work that a number in the area did in fact eat eggs occasionally.)

In a simple regression analysis, $83 \%$ of the variation in the least cost index calculated for the 71 foods could be explained by the variation in the least cost index calculated for the 17 'common' foods ( $\beta=0.823, R^{2}=0.826, P<0.001$ ). Similarly $77 \%$ of the variation in the mean price index calculated for the 71 foods could be explained by the variation in the mean price index for the 17 'common' foods ( $\left.\beta=0.799, R^{2}=0.773, P<0.001\right)$. However, reducing the number of foods which were costed to only 17 'common' foods, meant that a number of shops, in this case 15, dropped out of the analysis. In our study there was therefore a loss of information on 15 shops. These shops were mainly specialist: 11 butchers, five fishmongers and one newsagent. In order not to lose such specialist shops from the analysis, the cost of the cheapest fresh chicken portions (not wings) and the cost of the cheapest of fresh cod or haddock was added to the above

Table 2 Actual price variation for a subset of foods with standardized weights

\begin{tabular}{|c|c|c|c|c|}
\hline $\begin{array}{l}\text { Food item and } \\
\text { number of shops } \\
\text { stocking it }\end{array}$ & $\begin{array}{l}\text { Minimum price } \\
\text { within area }\end{array}$ & $\begin{array}{l}\text { Maximum price } \\
\text { within area }\end{array}$ & $\begin{array}{l}\text { Mean (SE) of shops } \\
\text { (not petrol stations, } \\
\text { newsagents or } \\
\text { off-licences) }\end{array}$ & $\begin{array}{l}\text { Mean (SE) of petrol } \\
\text { stations, newsagents } \\
\text { and off-licences }\end{array}$ \\
\hline 12 weetabix $(n=72)$ & $57 p$ & $£ 1.89$ & $82 p(0.012)$ & $86 p(0.018)$ \\
\hline Pint of semiskimmed milk $(n=100)$ & $27 p$ & $49 p$ & $38 p(0.007)^{*}$ & $41 \mathrm{p}(0.005) *$ \\
\hline $500 \mathrm{~g}$ pasta $(n=95)$ & $19 p$ & $£ 1.29$ & $64 p(0.023)^{*}$ & $74 p(0.035) *$ \\
\hline $800 \mathrm{~g}$ loaf of sliced white bread $(n=89)$ & $18 p$ & $89 p$ & $49 p(0.022)$ & $55 p(0.030)$ \\
\hline $800 \mathrm{~g}$ loaf of wholemeal bread $(n=48)$ & $25 p$ & $£ 1.02$ & $76 p(0.034)$ & $83 p(0.037)$ \\
\hline $410 \mathrm{~g}$ baked beans $(n=104)$ & $9 p$ & $59 p$ & $30 p(0.012) *$ & $34 p(0.016) *$ \\
\hline
\end{tabular}

$* t$-tests reveal that the difference between these prices is significant at the $95 \%$ confidence interval. 
Table 3 Foods used for condensed indices acceptable to four ethnic groups in a deprived area in London, plus chicken and fish

\author{
Wholemeal sliced bread, white bread \\ White pasta \\ Potatoes \\ Cornflakes \\ Apples \\ Bananas \\ Pears \\ Onion \\ Carrots \\ Tinned tomatoes \\ Fresh tomatoes \\ Cabbage \\ Fresh skimmed/semiskimmed milk \\ Low-fat fruit yoghurt \\ Eggs \\ Polyunsaturated spread \\ Oil \\ Chicken portions (not wings) \\ Fresh cod/haddock
}

index. These inclusions do not greatly increase $R^{2}$, but do ensure that all shops can be mapped; $84 \%$ of the variation in the least cost index calculated for the 71 foods could be explained by the variation in the condensed least cost index calculated for the 17 'common' foods, chicken and fish $\left(\beta=0.844, R^{2}=0.835, P<0.001\right)$. Similarly, $79 \%$ of the variation in the mean price index calculated for the 71 foods could be explained by the variation in the condensed mean price index for the 17 'common' foods, chicken and fish $\left(\beta=0.815, R^{2}=0.789, P<0.001\right)$.

\section{Availability indices and availability distribution}

Indices of availability can be easily calculated, given the binary nature of availability. In addition it is possible to provide an index of the number of fruits and vegetables, breakfast cereals, meats or fish at any one location, because questions were included as to the range of foods available in these categories. Figure 2 illustrates the fresh green availability index for the area, showing the availability of fruits and vegetables. Discussion of the availability of brands or availability according to type of shop is beyond the scope of this paper but will be disseminated in further work.

The availability of 123 foods or drinks, in various quantities, was checked in all outlets. A frequency count shows that the only fresh (i.e. not frozen, bottled, canned or dried) product available in more than $50 \%$ of outlets was milk. The most commonly available items were carbonated drinks ( $81 \%$ of all outlets sold them), low calorie carbonated drinks (79\%) and sweets and chocolates (72\%). Meats such as pork (10\%), goat (9\%) and beef mince (9\%) had low availability as did, unsurprisingly, fresh fish (6\%).

On average, only $27 \%$ of the items on the UK food list would be found in any given food shop, $26 \%$ of items on the African and Caribbean food lists, and $28 \%$ of items on the Gujarati Hindu food list. Hence, within this area, there was no significant difference in the mean availability of different ethnic foods. No shop stocked all the 71 foods which would make up all of the lists, the maximum being $61 \%$ of all 71 foods. The UK white list was the only one to be fully stocked, and that only in one superstore, although some shops did stock nearly $100 \%$ of the other ethnic food lists.

\section{Condensed availability index}

The use of the 'common' food list to produce a condensed availability index was also explored. Simple linear

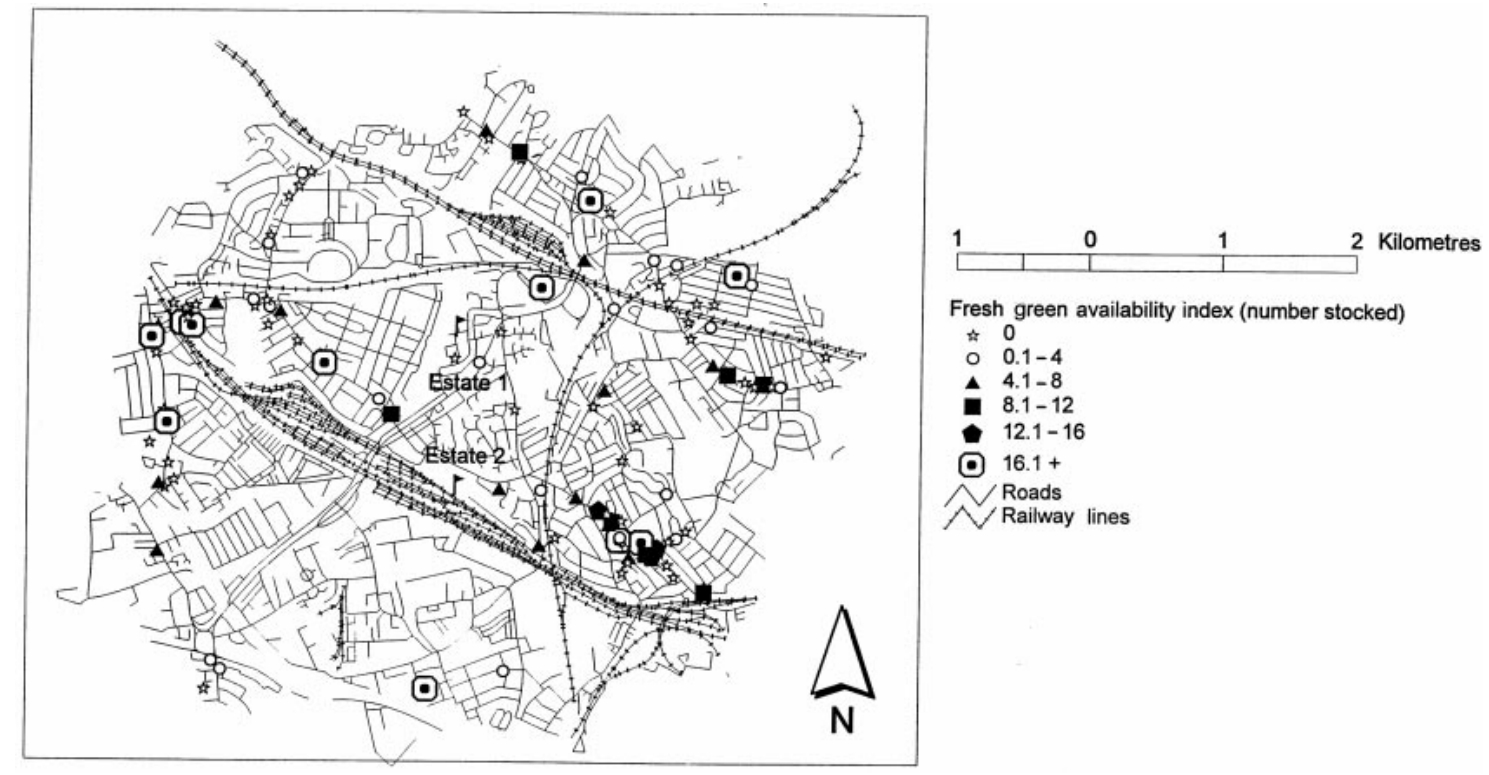

Fig. 2 Availability of fresh fruits and vegetables in a deprived area. (Data for map: (C) Automobile Association, for railways, and (c) Bartholomew, for roads) 
regression was conducted. The number of foods available on the 'common' food list in shops explained $67 \%$ of the variation in the total number of all foods available $(\beta=2.4$, $\left.R^{2}=0.669, P<0.001\right), 80 \%$ of the variation in the African foods stocked in shops $\left(\beta=1.82, R^{2}=0.803, P<0.001\right)$, $75 \%$ of the variation in Carribean foods in shops $(\beta=$ 1.74, $\left.R^{2}=0.752, P<0.001\right), 68 \%$ of the variation in Gujarati Hindu foods available in shops, and 91\% of the availability of UK foods in shops.

\section{Discussion}

This paper has presented a way to describe and map the cost and availability of food within an area. This contributes to the question of how one measures access by providing a means by which the cost and availability of foods within shops in an area can be compared against each other. The indices can then be linked to local geographical and economic information available from the census or sample surveys to provide a quick snapshot of subsections of an area which may be most at risk from a lack of access to an affordable, extensive range of food.

Thus the next stage of this research involves analysing these indices and the spatial spread of values with area measures such as distance to shops from populationweighted centroids within enumeration districts (approximately 140 households $)^{24}$. In conjunction with information on private car ownership, bus routes and timetables, this would provide data on area variations in physical access to reasonably priced shops. In addition data on enumeration district deprivation levels, available from local council data, can provide information on economic access. High deprivation levels are characterized by a high number of people on state benefits or low wages, who are more likely to need access to the cheapest shops. Cut-off points of reasonable access can also be developed given the cost of food in relation to income levels and the availability of food within a reasonable distance.

The indices could also be used to monitor changes in provision as a result of interventions to improve food access or a change in local retail provision.

Mapping this information using GIS software is seen to be of benefit. This paper presents a purely descriptive area map, yet, at a glance, one can see those areas where people would be nearer to reasonably priced foods which could contribute to a healthy diet.

A further stage is to test these methods in another area. This will investigate the reliability of the correlation between the 'condensed' indices and the 'all product' indices; the variation in terms of provision of ethnic foods; and whether there is substantial difference in mean prices between areas. We feel the methodology presented here could be applied to any area. The data assessed in this paper was collected within a $2-\mathrm{km}$ radius of a central point, an area which contained the vast majority of shops used by the local community, and which was sufficient to allow for comparisons within it. However, it may be appropriate to change the size of the area studied if there is low retail provision, or if the research is for a particular council or health board. An account of the sizes of areas which would need to be surveyed in order to encompass the majority of shops used by the residents of different urban and rural areas, would, in itself, provide useful information on variations in access throughout the country.

There are many ways in which these indices can be modified to present a picture of the price and/or availability of food in an area. Within this survey the data collector also rated quality of fresh fruit and vegetables subjectively on a five-point scale. It would, therefore, be possible to map indices reflecting just those fresh fruit and vegetables perceived as above average quality. A more rigorous approach to quality could be built into a similar data collection and analysis procedure if desired. In addition only those fruit and vegetables which are below average price could be mapped to provide an indication of the availability of reasonably priced fruit and vegetables. Another possibility may be to look at availability at different times of the day. Opening hours were collected for all shops; it could be possible to look at availability for example at 9 am, 2 pm or 2 am.

Within the area studied, preliminary results have shown that petrol stations in particular are expensive along with off-licences and newsagents. Prices were seen to vary tremendously for six products randomly chosen, with more than a four-fold difference between the cheapest price available in the area and the most expensive. Further work needs to identify if, and to what degree, any sectors of the community rely on such outlets for some or all of their food shopping.

Finally, we have reported on the fact that foods which are not traditionally seen as being integral to a healthy diet, such as carbonated drinks, sweets and chocolates, are more available than 'healthier' foods and drinks. Indeed, on average, fewer than a third of the foods which would contribute to make up a basic basket of foods for a healthy diet were stocked in most outlets.

Reasonable access is being able to obtain a variety of healthy foods at a reasonable price. This paper has developed indices which enable someone to define variations in variety and price and hence, with local indicators of economic and physical resources, monitor variations in access within an area. No such indices were available which could provide information on the relative cost of shops given what they stock. Researchers have costed healthy and unhealthy food baskets ${ }^{10-12}$, or compared the cost of a basket in one type of shop to another ${ }^{13}$, but this has meant that only those shops selling all the foods could be compared. This methodology goes one stage further and as such we have achieved targets to develop indices as outlined by the Low Income Project Team of the Nutrition Task Force ${ }^{16}$. 


\section{Acknowledgements}

This research has been funded by the NHS Executive. We have guaranteed anonymity to the area so cannot name the health authority collaborating with us. We wish to thank Moushumi Chaudhury for collecting the price and availability data.

\section{References}

1 Acheson D, Chair. Independent Inquiry into Inequalities in Health Report. London: HMSO, 1998.

2 Department of Social Security. Households Below Average Income: A Statistical Analysis, 1992/3-1979. London: HMSO, 1995.

3 Ministry of Agriculture, Fisheries and Food. National Food Survey 1996. London: HMSO, 1996.

4 Gregory J, Foster K, Tyler H, Wiseman M. The Dietary and Nutritional Survey of British Adults. London: HMSO, 1990.

5 Gregory JR, Collins DL, Davies PSW, Hughes JM, Clarke PC. National Diet and Nutrition Survey: Children Aged 1.5 to 4.5 Years. London: HMSO, 1995.

6 Department of Health. The Diets of British Schoolchildren. London: HMSO, 1989.

7 Bolton-Smith C, Smith WCS, Woodward M, Tunstall-Pedoe $\mathrm{H}$. Nutrient intakes in different social class groups: results from the Scottish Heart Health Study. Br. J. Nutr. 1991; 65: $321-5$.

8 Dobson B, Beardsworth A, Keil T, Walker R. Diet, Choice and Poverty: Social, Cultural and Nutritional Aspects of Food Consumption Among Low Income Families. London: Family Policy Studies Centre with the Joseph Rowntree Foundation, 1994.

9 National Children's Homes. NCH Poverty and Nutrition Survey. London: NCH, 1991.
10 Burrows C. Shopping Basket Survey. Manchester: University of Manchester Medical School, 1991.

11 Farringdon J. The Cost and Availability of Food from Shops and Cafes in Oldham. Oldham: West Pennine Health Authority Health Promotion Unit, 1994.

12 Mooney C. Cost and availability of healthy food choices in a London health district. J. Hum. Nutr. Diet. 1990; 3: 111-20.

13 Piachaud D, Webb J. The Price of Food: Missing Out on Mass Consumption. STICERD Occasional Paper 20. London: London School of Economics, 1996.

14 Department of Health. Our Healthier Nation: A Contract for Health. London: HMSO, 1998.

15 Noble M, Smith G, Avenell D, Smith T, Sharland E. Changing Patterns of Income and Wealth in Oxford and Oldham. Oxford: University of Oxford, 1994.

16 Department of Health. Low Income, Food, Nutrition and Health: Strategies for Improvement. A report from the Low Income Project Team to the Nutrition Task Force. London: Department of Health, 1996.

17 Dowler E. Food Poverty and Food Policy. IDS Bulletin. 29: 2, $58-65$.

18 Carstairs V, Morris R. Deprivation: explaining differences in mortality between Scotland and England and Wales. BMJ 1989; 299: 886-9.

19 Local Council. Directory of Social Indicators for Local Council. London: The Partnership and Research Unit and Environmental Planning and Commissioning, 1996.

20 Dovlo F, Grimble R, Orraca-Tetteh R. What Shall We Eat? Accra, Ghana: Asempa Publishers, 1985.

21 Health Education Authority. Nutrition in Minority Ethnic Groups: Asians and Afro-Caribbeans in the United Kingdom. London: HEA, 1991.

22 Whitby P. Foods of Ghana. Food Research Institute Res. Bull. 1968; 1: 1-31.

23 Harris JB. Sky Juice ... and Flying Fish: Traditional Caribbean Cooking. New York: Simon and Schuster, 1991.

24 Donkin AJM, Dowler E, Stevenson S, Turner S. Mapping access to food at a local level. Br. Food J. 1999; 101: 554-64. 